\title{
Psychosocial factors and public health
}

\section{A Singh-Manoux}

\section{Another point of view (see page 565)}

M acleod and Davey Smith state that the aim of their paper is to critically examine the role of psychosocial factors in health. ${ }^{1}$ Unfortunately, what could have been an interesting discussion is compromised by the authors implicit assumption that there is a single pathway linking social position to health. The authors seem to equate parsimonious causal analysis with a narrow, reductionistic perspective, subsequently devoting most of their paper to a discussion of "psychosocial versus material explanation", while ignoring evidence showing multiple pathways linking social position to health. ${ }^{23}$

This commentary widens the debate by considering three issues:

\section{(1) PSYCHOSOCIAL VARIABLES: DEFINITION AND THEIR IMPORTANCE TO HEALTH}

Psychosocial variables encompass two categories of variables. The first consists of psychological attributes like hostility, depression, hopelessness, etc, which exist at the individual level, and are likely to be a result of the process of socialisation. The second category is more structural in nature, work conditions for example. These two categories work synergistically at the individual level, as can be seen from social support at work, which is a function of both work conditions and personal social interaction skills. Although the authors start out with a similar definition of psychosocial variables, in fact they interpret them rather narrowly as being the way in which "poor people feel about their poverty". This restrictive view of psychosocial variables negates the importance of the ubiquitous association between social disadvantage and a host of psychosocial variables in the developed world. We still know very little about the mechanisms that create and sustain this link, and when in the lifecourse this link is established.

In considering the importance of psychosocial variables to health Macleod and Davey Smith create a false dichotomy between "objective disease" and "misery". They themselves acknowledge "misery" to be a legitimate public health issue, particularly in the developed world with increasing life expectancies. It may be important to examine the links between "misery" and lifestyle in light of the World Health Organisation claim that "lifestyle-related diseases and conditions are responsible for $70-80 \%$ of deaths in developed countries". ${ }^{4}$

The authors also discuss the part played by "reporting bias" (people who report feeling miserable also report feeling ill) in explaining the association between psychosocial exposure and illness. However, one feels that this is a diversion as the authors go on to cite evidence showing psychosocial exposures to be associated with "objective" health outcomes.

\section{(2) SOCIAL STRUCTURE AND HEALTH: ARE PSYCHOSOCIAL VARIABLES ON THE PATHWAY?}

The relative importance of different pathways linking social position to

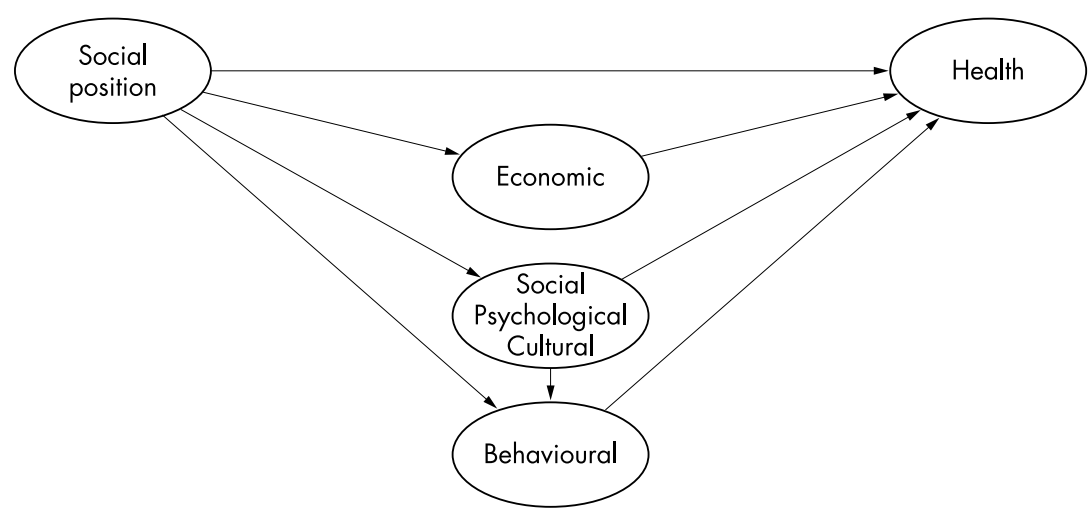

Figure 1 Relation between social position and health.

health can only be assessed if these pathways are modelled simultaneously, something that has not yet been attempted. The causal sequence would be A (social position) leading to $X$ (various pathways: social, cultural, psychological, and economic) that in turn leads to B (ill health). The authors accept the existence of this causal chain: both the link between A and psychosocial-X, and that between psychosocial-X and health. Attempts to assess the impact of the psychosocial pathway, or any other pathway, on health needs to be carried out within this sequential causal framework. Neglect of temporal order by treating psychosocial variables as another subset of factors along with measures of social position in multiple regression type analysis has been shown to systematically underestimate their role in disease aetiology. ${ }^{5}$ It is therefore necessary to envisage new ways of examining the links between social structure and health.

Figure 1 shows a simple example of the way in which the relative importance of different pathways linking social structure to health could be modelled. This causal model respects the sequential relation between the variables, paying heed to the importance of distinguishing between proximal and distal variables in a causal chain. ${ }^{56}$ Structural equation modelling (SEM) would allow the relative size of each of these pathways to be assessed. SEM has the added advantage of allowing latent constructs to be modelled, enabling a comprehensive assessment of all variables in the model. There are some recent examples of $\mathrm{SEM}^{78}$ and alternative approaches to modelling pathways in the literature, ${ }^{910}$ demonstrating the way in which complex analytical techniques can be used to answer complex questions.

To assess the "independent effect" of psychosocial variables, Macloed and Davey Smith put their faith in the counterfactual model of causation. The basis of establishing causality here is the probability of disease in the exposed group that would have occurred had they not been exposed. As random assignment of psychosocial variables is not feasible, the authors recommend an examination of the impact of psychosocial interventions. However, psychosocial intervention studies are unlikely to shed any light on the importance of psychosocial variables. This is primarily because the counterfactual contrast being set up is meaningless if social structure is inextricably associated with psychosocial variables. ${ }^{11}$ Let us take the example of a "psychosocial intervention" set up to improve social support at work for the socially disadvantaged group. This would involve achieving a minimum of two things: fundamental changes in the structure of work, and instant learning of appropriate 
social skills normally acquired over the lifecourse. The near infeasibility of such an intervention is clear. The way ahead entails choosing appropriate statistical models that reflect advances in conceptual and theoretical models.

\section{(3) PSYCHOSOCIAL VARIABLES AND POLICY IMPLICATIONS}

Macleod and Davey Smith are quite right in stating that amelioration of social inequality in health is a priority for public health policy in most economically developed countries. However, they believe that "psychosocial solutions do not necessitate fundamental social change", while accepting the causal link between social disadvantage and psychosocial adversity. It seems difficult to understand how psychosocial change would work without a change in social inequality to which it is causally linked. This commentary calls for a push in social epidemiology towards understanding the mechanisms by which social structure influences psychosocial variables. Socialisation agents may be responsible, and the part played by parents, schools, and other agents needs to be elucidated. Policy should also be directed towards improving the structural aspects of psychosocial variations, in terms of work structure, work-life balance, etc. Psychosocial variables are important both because they affect quality of life ("misery") and are on the causal pathway to somatic disease. ${ }^{12}$ As public expenditure on health encompasses both these outcomes, policy implications need to address them both.

In conclusion, any discussion on psychosocial variables is welcome as it is likely to promote development of both theory and method aimed at understanding the links between social structure and health.

\section{$J$ Epidemiol Community Health 2003;57:553-554}

\section{Author's affiliations}

A Singh-Manoux, International Centre for Health and Society, Department of

Epidemiology and Public Health, University College London, 1-19 Torrington Place, London WCIE 6BT, UK

Correspondence to: Dr A Singh-Manoux; A.Singh-Manoux@public-health.ucl.ac.uk

\section{REFERENCES}

1 Macleod J, Davey Smith G. Psychosocial factors and public health: a suitable case for treatment? J Epidemiol Community Health 2003;57:565-70
2 Davey Smith G, Hart C, Hole D, et al. Education and occupation social class: which is the more important indicator of mortality risk? J Epidemiol Community Health 1998;52:153-60.

3 Marmot $M$, Theorell T. Social class and cardiovascular disease: the contribution of work. Int J Health Serv 1988; 18:659-74.

4 World Health Organisation. The world health report. Geneva: WHO, 1995.

5 Weitkunat R, Wildner M. Exploratory causal modeling in epidemiology: are all factors created equal? J Clin Epidemiol 2002;55:436-44

6 Singh-Manoux A, Clarke P, Marmot M. Multiple measures of socioeconomic position and psychosocial health: proximal and distal effects. Int J Epidemiol 2002;31:1 192-9.

7 Chandola T, Bartley M, Sacker A, et al. Health selection in the Whitehall II study, UK, Soc Sci Med 2003:56:2059-72.

8 Eamonn F, James D, O'Hehir F, et al. Pilot study of the roles of personality, references, and personal statements in relation to performance over the five years of a medical degree. BM 2003;326:429-32.

9 Didelez V, Pigeot I, Dean K, et al. A comparative analysis of graphical interaction and logistic regression modelling: self-care and coping with a chronic illness in later life. Biometrical J 2002;44:410-32.

10 Greenland S, Brumback B. An overview of relations among causal modelling methods. Int J Epidemiol 2002;31:1030-7.

11 Kaufman JS, Cooper RS. Seeking causal explanations in social epidemiology. Am J Epidemiol 1999;150:113-20.

12 Marmot M, Wilkinson RG. Psychosocial and material pathways in the relation between income and health: a response to Lynch et al. BM 2001;322:1233-6.

\section{Authors' reply}

W e are sorry that Dr SinghManoux felt our discussion was not as interesting as it could have been, and while we recognise that this is necessarily true, her rejoinder leaves us unclear as to why she feels this way. Most of the points she raises in her commentary relate to areas we discussed in some detail.

Dr Singh-Manoux accuses us of "ignoring evidence showing multiple pathways linking social position to health". On the contrary, we did exactly the opposite. In our view there are multiple but specific pathways between social position and health outcomes, as we have discussed in depth elsewhere. ${ }^{1}$ Examples include childhood living conditions that predispose to Helicobacter pylori acquisition and (many decades later) adult stomach cancer risk. The current social patterning of adult stomach cancer risk is thus the outcome of material processes acting in the early years of life. ${ }^{1}$ Conversely an adult income that allows the purchase of airline tickets to sunny places, thus increasing the risk of melanoma or death in plane crashes, explains why these two causes of death often show a strong positive social gradient. ${ }^{1}$ While recognising the fact that psychosocial experiences reflect events in the external world impacting on the micro-processes of brains of individuals, we will refer to "material" causes in this response as those aspects of the world that will influence health independent of the psychological response they engender.

Recognition of these (and many other ${ }^{1}$ ) specific pathways is explicitly opposed to the "general susceptibility" theories that underlie much of the psychosocial discourse $e^{2}$; it is in the psychosocial literature that one reads of how psychoneuroendocrine pathways mediate between the external psychosocial environment and nearly every health problem imaginable. $^{3-5}$ In our paper we acknowledge that many factors (including psychosocial factors) are associated with social position, and hence potentially with health, as health is socially patterned. Our central concern, as public health scientists, should be to establish which of these associations are causal, rather than merely correlational. We need to make this distinction because non-causal associations will not form the basis for effective interventions to improve population health and reduce health inequalities. We have made no a priori implicit assumption that only material pathways link social position to health, and have only argued that the evidence should be examined critically. But we make no apology for continuing to emphasise the probable key role for material factors. Across all the different classification schemes what, fundamentally, defines differences in social position? ${ }^{6}$ We suggest, differences in the power to access material assets and, linked to this, the power to make healthy choices. Wealth is required to convert knowledge to health.?

However, as we clearly stated, the main purpose of our paper was not to consider the evidence for a material causal hypothesis in relation to social health inequalities. Rather it was to consider the evidence for the psychosocial causal hypothesis. Most of this evidence is observational, and is therefore subject to considerable problems of interpretation. ${ }^{8}$ One of these is reporting 
bias. It is interesting that Dr SinghManoux feels that this is a "diversion". In fact, much of the evidence in this area of research, such as that from the Whitehall II study, has been based on links between psychosocial factors and physical health outcomes assessed from self reports. ${ }^{9}$ A comparison of these relations with those involving the few objective physical health measures thus far reported from Whitehall shows the latter to be considerably weaker. ${ }^{10}$ We reproduce these data in table 1 , alongside our own from the West of Scotland Collaborative Study ${ }^{11}$ - which provide clear evidence of reporting bias - to allow readers to make their own assessment. Other than as a reflection of reporting bias, how should we explain these findings?

Perhaps even more important, is the issue of confounding - are psychosocial exposures themselves health damaging or are they merely markers for other factors that are causally related to physical health? ${ }^{12}$ As Dr Singh-Manoux notes, there currently appears an almost ubiquitous association between general social disadvantage and a host of psychosocial variables in the developed world. She then seems to chastise us for our neglect of the question as to why such factors may be linked to social position. Are we the only readers of the JECH who feel that it is scarcely mysterious that a lifetime of social disadvantage and disenfranchisement may be associated with negative feelings in the individual experiencing such hardship? However, simply because the basis of the relation between disadvantage and bad feeling is self evident it does not follow that bad feeling self evidently causes objective physical disease. Bad feelings are clearly a bad thing, but they may not be on the pathway between social disadvantage and objective physical disease as Dr Singh-Manoux claims.

Dr Singh-Manoux then raises the issue of the behavioural or "lifestyle" pathway between negative feelings and poorer health. We are far more accustomed to hearing the argument that neuroendocrine pathways represent the main mechanism by which psychosocial factors "get under the skin". ${ }^{13}$ Social gradients in heart disease in Whitehall were, after all, equally apparent among lifelong non-smokers. ${ }^{14}$ Furthermore, adjustment for lifestyle measures only partly attenuated most of the social inequalities in physical health reported from Whitehall. ${ }^{14}{ }^{15}$ In our own data from Scotland, higher stress was indeed associated with less healthy lifestyle but not with poorer health. ${ }^{11}{ }^{12}$ So we agree with Dr Singh-Manoux, that negative feelings may, depending upon context, feed into unhealthy lifestyles. However the coincidence of some unhealthy behaviours with social disadvantage is comparatively recent: in $195053 \%$ of physicians

Table 1 Associations between perceived stress and job control and subjective and objective outcomes in the West of Scotland Collaborative Study and the Whitehall II Study

\begin{tabular}{lll}
\hline Outcome type & Effects in Collaborative Study ${ }^{11}$ & Effects in Whitehall II Study ${ }^{10}$ \\
\hline Fully subjective* & & \\
High exposure & $2.66(1.61$ to 4.41$)$ & $2.02(1.22$ to 2.34$)$ \\
Medium exposure & $1.37(0.91$ to 2.08$)$ & $1.44(0.86$ to 2.39$)$ \\
Low exposure & 1.00 & 1.00 \\
Fully objective** & $0.67(0.36$ to 1.26$)$ & $1.17(0.8$ to 1.8$)$ \\
High exposure & $1.03(0.71$ to 1.49$)$ & $1.16(0.8$ to 1.7$)$ \\
Medium exposure & 1.00 & $1.00 \ddagger$ \\
$\quad$ Low exposure & 1.00 \\
\hline
\end{tabular}

*Rose angina in both studies; †ECG abnormalities (Minnesota coding system) in both studies. All estimates adjusted for age, social position, and cardiovascular risk factors other than $\ddagger$ (only unadjusted estimates were reported in the paper).

in the US smoked, compared with $40 \%$ of all adults. ${ }^{16}$ Lifestyle thus seems an incomplete explanation, as suggested by the above evidence, for current social health gradients. The determinants of behaviour are complex and the generally unimpressive effects of individually targeted interventions aimed at modifying behaviour should remind us of this.

In our paper we discuss general strategies for drawing causal inference in health science. We are happy to agree with Dr Singh-Manoux that, when prospective observational data are all that are available, there may well be a place for greater use of the graphical approaches, including structural equation modelling, that she suggests. However we reiterate our points regarding the limitations of analytical sophistication in resolving these issues, as exemplified by the recent cases of antioxidant vitamins and hormone replacement therapy, where strong observational evidence of protective effects against heart disease has been overturned by randomised controlled trial evidence. ${ }^{17}$ We disagree with Dr Singh-Manoux's dismissal of the role of experimental studies in this regard, and with her interpretation of

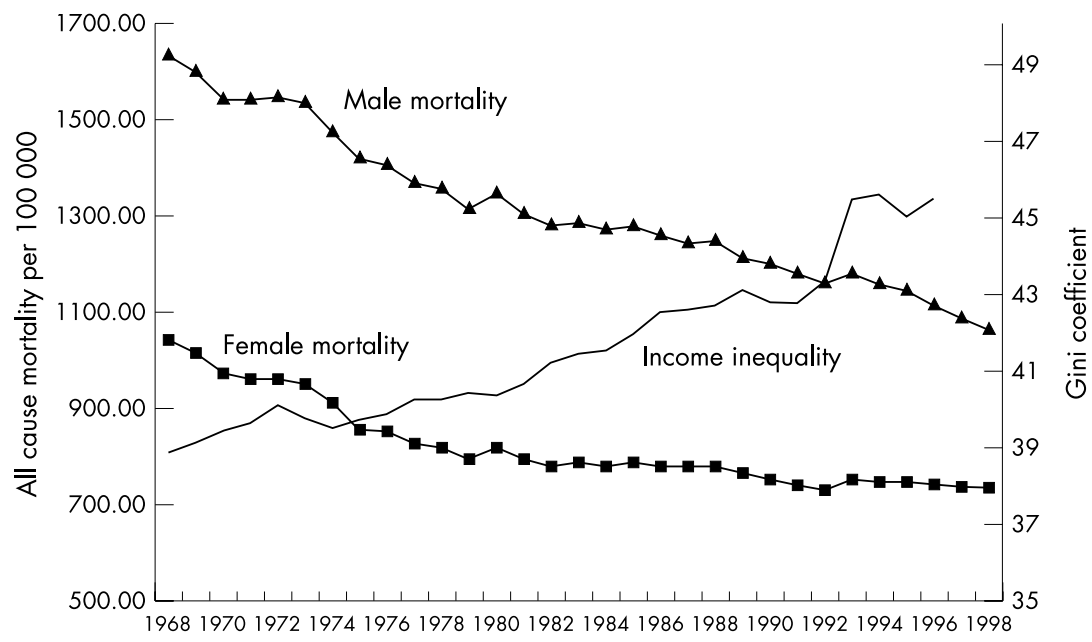

Figure 1 Income inequality (Gini) and sex specific, age adjusted, all cause mortality USA, $1968-1998$ the work of Weitkunat and Wildner, who basically develop the ongoing argument as to whether it is appropriate to adjust for covariates that may be causal intermediates-rather than confounders-in statistical models. ${ }^{18}$ They show that such adjustment will tend to accentuate apparent effects of factors more proximal to the outcome. In other words in the case of psychosocial factors that may mediate the relation between social position and health adjustment will tend to lead to the psychosocial measure appearing to have an effect "independent" of that of the more distal (and perhaps determining) social position measure. Psychosocial exposures are amenable to experimental could they form the basis for useful health interventions? Experiment remains the most powerful means of reducing the risk of being misled by confounding and selection bias (with "Mendelian randomisation" - in essence a natural experiment-a close second).$^{22}$ We doubt that Dr Singh-Manoux is really suggesting that we abandon randomised controlled trials in favour of observational studies analysed using structural manipulation. ${ }^{19-21}$ If they weren't how 
equation modelling as an approach to determining causation and the loci for health interventions. It seems unlikely that the methods she proposes, if applied to observational data on, say, hormone replacement therapy and heart disease risk would have led to reaching the right conclusions either.

Dr Singh-Manoux states that, "psychosocial intervention studies are unlikely to shed any light on the importance of psychosocial variables." We think this is an ill considered assertion based on her idea that changing psychosocial exposure, without changing the social structure that it is imbedded within, will be difficult. This is of course true; in fact we made this very point in our paper and elsewhere. ${ }^{23}$ But such difficulty notwithstanding, we agree with Kuper, Marmot, and others, that intervention studies are the bullet that psychosocial epidemiology has to bite if it is to influence policy. ${ }^{24-26}$ Experimental studies in this area will provide better evidence on true causality than observational studies, however cleverly the latter are analysed. More importantly they will tell us how, if at all, these causal relations might lead to effective public health policy.

We did not touch upon population health in our paper, but one of the key issues with respect to viewpoints that see a primary psychosocial determination of health is that it makes little sense in regard to trends in overall population health. Factors such as income inequality (and presumably the feelings associated with it), and indices of "social capital" such as rates of participation in the electoral process have all deteriorated over a period when mortality rates have declined (fig 1). ${ }^{27-31}$ Of course the contribution of psychosocial factors may differ by particular outcomes and may be complicated by differing time lags between exposure and disease. Nevertheless, perspectives that take into account the life course influences of particular material factors on specific health outcomes are largely congruent with population health trends. ${ }^{132}$

We argued for the need to critically examine the evidence supporting a causal role for psychosocial exposures on objective disease and raised issues of reporting bias and confounding in that regard. Considering these issues is standard practice in epidemiology, we ask nothing more from the study of psychosocial exposure than is asked in other areas of population science. And to reiterate, the human misery generated by unfair and unequal societies is unquestionably a bad thing. However, whether it is also a significant cause of physical disease seems unclear; clarifying this issue is important because it has implications for how policy might effectively improve peoples' health in both relative and absolute terms.

\section{J Epidemiol Community Health}

2003;57:554-556

\section{Authors' affiliations}

J Macleod, Department of Primary Care and General Practice, University of Birmingham, UK G Davey Smith, Department of Social

Medicine, University of Bristol, UK

\section{REFERENCES}

1 Davey Smith G, Gunnell D, Ben-Shlomo Y. Life-course approaches to socio-economic differentials in cause-specific adult mortality. In: Leon D, Walt G. Poverty, inequality and health. Oxford: Oxford University Press, 2000:88-124.

2 Syme SL, Berkman LF. Social class, susceptibility and sickness. Am J Epidemiol 1976;104:1-8.

3 Selye $\mathbf{H}$. The stress of life. New York: McGraw Hill, 1956.

4 Brunner E. Stress and the biology of inequality. BM 1997;314:1472-6.

5 Garrsen B. Psycho-oncology and cancer: linking psychosocial factors with cancer development. Ann Oncol 2002;13 (suppl 4):171-5

6 Wright EO. Class counts. Cambridge: Cambridge University Press, 2000.

7 Johansson SR. Death and the doctors medicine and elite mortality in Britain from 1500 to 1800. Cambridge: Cambridge Group for the History of Population and Social Structure Working Paper Series number 7 , 1999

8 Rellman AS, Angell M. Resolved: psychosocial interventions can improve clinical outcomes in organic disease (Con). Psychosom Med 2002;64:558-63.

9 Bosma H. Marmot MG. Hemingway H, et al. Low job control and risk of coronary heart disease in Whitehall II (prospective cohort) study BM 1997;314:558-65.

10 Stansfeld SA, Fuhrer R, Shipley M, et al. Psychological distress as a risk factor for coronary heart disease in the Whitehall II study. Int J Epidemiol 2002; 31:248-55.

11 Macleod J, Davey Smith G, Heslop P, et al. Psychological stress and cardiovascular disease: empirical demonstration of bias in a prospective observational study of Scottish men. BM 2002;324:1247-51.

12 Macleod J, Davey Smith G, Heslop P, et al. Are the effects of psychosocial exposures attributable to confounding? Evidence from a prospective observational study on psychological stress and mortality. J Epidemio Community Health 2001:55:878-84.

13 Brunner E. Stress mechanisms in coronary heart disease. In Stansfeld SA, Marmot MG, eds. Stress and the heart: psychosocial pathways to coronary heart disease. London: BM Books, 2002:181-99.
14 Marmot $M$. Occupational therapy or the major challenge? Int J Epidemiol 2002;31:1122-4.

15 Marmot MG, Bosma $\mathrm{H}$, Hemingway $\mathrm{H}$, et al. Contribution of job control and other risk factors to social variations in coronary heart disease incidence. Lancet 1997;350:235-9.

16 Tate C. Cigarette wars: the triumph of "the little white slaver". Oxford: OUP, 1999

17 Davey Smith G, Ebrahim S. Data dredging, bias or confounding BM 2002;325: 1437-8

18 Weitkunat R, Wildner M. Exploratory causal modelling in epidemiology: are all factors created equal? J Clin Epidemiol 2002;55:436-44.

19 Patel C, Marmot MG, Terry DJ, et al. Trial of relaxation in reducing coronary risk: four yea follow-up. BM 1985;290: 1 103-6.

20 Orth-Gomer K, Eriksson I, Moser V, et al. Lipid lowering through work stress reduction. Int J Behav Med 1994;1:204-14.

21 Linden W, Stossel C, Maurice J. Psychosocia interventions for patients with coronary artery disease: a meta-analysis. Arch Intern Med 1996; 156:745-52.

22 Davey Smith G, Ebrahim S. "Mendelian randomisation": can genetic epidemiology contribute to understanding environmental determinants of disease? Int J Epidemiol 2002;32: 1-22

23 Lynch JW, Davey Smith G, Kaplan GA, et al. Income inequality and mortality: importance to health of individual income, psychosocial environment, or material conditions. BM 2000;320:1200-4

24 Kuper H, Marmot M. Job strain, job demands, decision latitude, and risk of coronary heart disease within the Whitehall II study. J Epidemiol Community Health 2003;57:147-53.

25 Pickering T. Job stress, control and chronic disease: moving to the next level of evidence. Psychosom Med. 2001;63:734-36.

26 Burg M, Berkman L. Psychosocial interventions in coronary heart disease. In: Stansfeld SA, Marmot MG, eds. Stress and the heart: psychosocial pathways to coronary heart disease. London: BM Books, 2002:278-93.

27 Lynch J, Davey Smith G. Rates and states: reflections on the health of nations. Int Epidemiol (in press)

28 Szreter S. The population health approach in historical perspective. Am J Public Health 2003:93:421-31.

29 Lindert PH. When did income inequality rise in Britain and America? J Income Distribution 2000;9: 11-25.

30 US Census Bureau. Reported voting and registration by race, Hispanic origin, sex and age groups, November 1964-2000. [Web page]. 2002. Available at http://www.census.gov/population/www/ socdemo/voting.html. (Accessed 20 Mar 2003).

31 US Census Bureau. Reported voting and registration by region, educational attainmen and labor force: November 1964 to 2000. [Web page]. 2002. Available at http://www.census.gov/population/www/ socdemo/voting.html. (Accessed 20 Mar 2003).

32 Leon DA. Common threads: underlying components of inequalities in mortality between and within countries. In: Leon $D$ Walt G. Poverty, inequality and health. Oxford: Oxford University Press, 2000:58-87. 
Suicide

\section{Unemployment and suicide}

\section{A Preti}

\section{How is your work going?}

T he prevention of suicidal behaviour is still a land of hopes and promises but not of certainties. In fact, Western countries are facing a general decline in suicide rates that seems unrelated to any national plan aimed at obtaining the desired outcomes in those situations that are known to be associated to suicidal behaviour.' General improvement in living conditions, better access to care, and more effective treatments of mental disorders are the most probable reasons for the recent decrease in suicide rates in many countries. However, the most recent financial-economic turmoil and the current threatening climate of permanent war will have a foreseeable impact on the standard of living, the consequences of which are still to be evaluated.

Socioeconomic events are known to produce important fluctuations in suicide mortality. Unemployment, in particular, seems related to suicide risk along direct and indirect pathways. Blakely and coworkers' paper in this issue ${ }^{2}$ adds to evidence indicating a causal association between unemployment and suicide. Their results indicate that this association is not attributable to confounding factors linked to the socioeconomic status and that it is only partly related to health selection or mental disorders. Statistical analyses permit the authors to calculate that mental illnesses account for about half of the deaths, however the effect of unemployment cannot be discounted solely on this basis. In longitudinal studies unemployment predates symptoms of depression. ${ }^{3}$ Moreover, the lack of economic independence as a result of unemployment reduces the possibility of using social and health services appropriately: this may prejudice compliance with therapeutically prescribed treatments, contributing to a worsening in the course of a mental disorder.

The most disruptive effect of unemployment, however, acts on social ties at both individual and community level. Measures of social fragmentation, indeed, were found to predict the risk of death by suicide and alcohol related diseases. ${ }^{4}$

Socioeconomic variables are likely to contribute to the impact of employment status on suicide. In the USA, the lower the socioeconomic status, the higher the suicide risk. However, unemployment adds independently to suicide risk in both men and women. ${ }^{25}$ Other recent studies found that exposure to unemployment is related to suicidal ideation and behaviour, even when taking into account known psychosocial confounding factors and reverse causality. ${ }^{6}$ Unemployment, therefore, should be considered a true risk factor for suicide.

To exploit this increased awareness of the role of unemployment in the pathways to suicide, however, we need to infuse a creative effort that may take us a little ahead of common sense.

At a first glance, it would seem that the role of clinicians and researchers in fostering public awareness on the role of social factors in negative psychological outcomes would merely end in supporting public welfare programmes. However, suicide rates were found to increase over time in the states that had reduced their per capita expenditure for public welfare; conversely, states that spend more on public welfare also have lower suicide rates.

This is not, however, the whole story. A closer look at the pathways from unemployment to psychological maladjustment and-hence-to suicide could permit the definition of reasonably practicable strategies aimed at preventing the most negative outcomes.

Job loss usually comprises a whole sequence of stressful events, from anticipation of job loss, to job search, and training for re-employment, when possible. Exclusion from ordinary living patterns, customs, and activities arising from a lack of resources adds independently to the stress caused by job loss, and further increases the risk of depression and subsequent suicide. It is therefore mandatory, whenever a lasting period of unemployment is foreseeable, particularly when middle aged people encounter job loss because of factory closure, to supply a psychological counselling service that may replace the informative, emotional, and material supportive resources diverted by unemployment.

Some pioneering studies found that psychological counselling programmes could prevent the decline in self esteem and mood that generally occurs after being made unemployed. ${ }^{8}$ Although such a service might be seen by trade unions as an attempt to counteract naturally occurring workers' rage, and deprive them of the emotional energies useful to carry on conflicts for employment, as perhaps the poorest protocols provide for, a sympathetically lead programme could permit maintaining an adequate psychosocial functioning and the early identification of the most severe disorders, thus preventing their worst outcomes.

Moreover, as it implies a contraction of a person's social network and a relevant change in the time structure in daily life, job loss may lead to a reduction in surveillance that, together with the availability of lethal means, is another key element in suicide, particularly among mentally troubled people. An effort to provide families with adequate information on this topic could be implemented through first level health resources-that is, the network of general practitioners.

Unemployment is also a considerable source of social stress leading to increased family tensions, increased isolation from others, and the loss of self esteem and confidence. The loss of employment, indeed, implies the loss of social contact and activity, and often leads to the severing of social ties. A well integrated social network plays an important protective part in maintaining mental health, offering support, guidance and assistance, favouring compliance with medical or psychiatric treatment and offering swift aid in the case of a self destructive act. Again, increasing access to health services and resources might reduce the negative impact of job loss. Multiplying the points of entry to the health network, even using the still unexplored potentiality of the internet, ought to favour access to treatment when necessary.

A different set of explanations, grouped under the "health selection" hypothesis, asserts that poorer health by itself, including poorer mental health, increases the risk of unemployment: thus, having a disorder that implies a higher risk of suicide would also lead to unemployment. Even assuming this explanation, which Blakely and coworkers' paper seems to discount, providing support and working opportunities to mentally suffering patients would protect them from the risk of suicide. In a 20 year prospective study on a large sample of psychiatric outpatients, unemployment was the most evident social factor that had an impact on suicide risk together with clinical ones, such as suicide ideation, and major depressive and bipolar disorders. ${ }^{9}$ Whenever possible, any effort should be done to keep all the patients with a mental disorder employed.

Paying attention to the immediate health consequences of unemployment also could produce lasting positive effects on public spending. It is interesting to see that growing financial difficulties, 
which are likely to be linked to rising unemployment rates, are also associated to an increased use of public funded facilities. From 1988 to 1994, for example, the number of patients discharged from US hospitals with a diagnosis of a mental illness increased from 1.4 to 1.9 millions over the whole period..$^{10}$ In particular, the rate of discharges with a diagnosis of a severe mental illness significantly increased from 196 to 314 per 100000 of the general population. It seems that the change in mental health care provision that occurred in the USA with the institution of the Medicaid program diverted the most severe patients to the public sector, so that public programmes have increasingly replaced private insurance as the most important source of payment in the USA.

Being creative in counteracting the most negative consequences of unemployment could therefore usefully interlace with current active public health programmes, which emphasise costs containment and saving. Any effort will be in vain, however, if the clinicians fail to use the most sensitive instrument they have: the ability to listen to patients and their families' complaints. Always ask: how is your work going?

$J$ Epidemiol Community Health 2003;57:557-558

\section{Author's affiliations}

A Preti, Department of Psychology, University of Cagliari, and Genneruxi Medical Centre, Cagliari, Italy

Correspondence to: Dr A Preti, Centro Medico Genneruxi, via Costantinopoli 42, 1-09129, Cagliari, Italy; apreti@tin.it

\section{REFERENCES}

1 De Leo $\mathbf{D}$. Why are we not getting any closer to preventing suicide? Br J Psychiatry 2002;181:372-4.

2 Blakely TA, Collings SCD, Atkinson J. Unemployment and suicide. Evidence for a causal association? J Epidemiol Community Health 2003:57:594-600.

3 Dooley D, Catalano R, Wilson G. Depression and unemployment: panel findings from the Epidemiological Catchment Area study. Am J Community Psychol 1994;22:745-65.

4 Whitley E, Gunnell D, Dorling D, et al. Ecological study of social fragmentation, poverty, and suicide. BM 1999;319:1034-7.

5 Kovesowa AJ Unemployment and suicide:

Kposowa AJ. Unemployment and suicide: cohort analysis of social factors predicting suicide in the US National Longitudinal Mortality Study. Psychol Med

2001;31:127-38

6 Fergusson DM, Horwood L, Woodward LI. Unemployment and psychosocial adjustment in young adults: causation or selection? Soc Sci Med 2001;53:305-20.

7 Zimmerman SL. States' spending for public welfare and their suicide rates, 1960 to 1995: what is the problem? J Nerv Ment Dis 2002;190:361-3.

8 Proudfoot J, Guest D, Carson J, et al. Effect of cognitive-behavioural training on job-finding among long-term unemployed people. Lancet 1997;350:96-100.

9 Brown GK, Beck AT, Steer RA, et al. Risk factors for suicide in psychiatric outpatients: a 20-year prospective study. J Consult Clin 20-year prospective study.

10 Mechanic D, McAlpine DD, Olfson M. Changing patterns of psychiatric inpatient care in the United States, 1988-1994. Arch Gen Psychiatry 1998;55:785-91.

\section{Unemployment and suicidal behaviour}

\section{Lester, B Yang}

\section{The role of economic policy}

t

n the mid-1980s, Stephen Platt published two reviews of the literature that indicated that unemployment was associated with an increased risk of completed suicide and an increased risk of attempted suicide (sometimes referred to as parasuicide). ${ }^{12}$ As we have pointed out, the association between unemployment and suicidal behaviour seems to be more reliable at the individual level than at the aggregate level. ${ }^{3}$ For example, in time series studies of 14 nations with available data for the period 1950-1985, Lester and Yang found a positive association between unemployment and completed suicide rates in only 10 nations, and this association was statistically significant in only four nations. ${ }^{4}$

The article by Tony Blakely and his colleagues in this issue of the journal provides excellent support for the association between unemployment and completed suicide at the individual level. ${ }^{5}$ The use of national records in a single country for over 2 million 18-64 year olds provides a sample far greater than samples used in previous research, and the inclusion of control variables makes the conclusions of the study more meaningful.
For future research, there are several issues that need to be addressed. Firstly, the discrepancy between the results of studies at the individual level and at the aggregate level needs to be addressed. Why do time series studies of unemployment and suicide rates fail to find a consistent association, an inconsistency found also in cross sectional studies over, for example, regions within a county? This discrepancy between the results of what we have called macrosocionomic and microsocionomic research designs ${ }^{6}$ is common to many phenomena in the social and behavioural sciences and raises difficult problems for sociological theories.

Secondly, the role of mental health in the association between unemployment and suicidal behaviour needs to be explored further. Does unemployment increase the risk of serious psychiatric problems that in turn increase the risk of suicidal behaviour or, alternatively, are those with psychiatric problems more likely to become unemployed and also more likely to engage in suicidal behaviour?

Ezzy has noted, in his review of the association between unemployment and mental health, that unemployment does not always result in worse mental health. ${ }^{7}$ Indeed, a minority of people show an increase in psychological wellbeing once they become unemployed. For which people does unemployment have a deleterious impact (including an increased risk of suicidal behaviour) and for which people does it have a beneficial impact?

Blakely and his colleagues in their article in this issue, using indirect methods, argue that about half of the increased risk of death from suicide is attributable to the mediating role of the increased level of mental illness. Eventually, the issue of the role of mental illness in the association between unemployment and suicidal behaviour can be resolved only by a study of people who receive adequate psychiatric evaluations while employed and subsequently when unemployed, together with appropriate control groups.

The association between unemployment and suicidal behaviour also raises another issue, one concerning public policy decisions. At the present time, before construction projects are approved by governments (local and national), environmental impact statements are demanded and, if the environmental impact is considered to be too harmful, the project may be delayed and even forbidden. Threatening the extinction of a rare species or introducing toxic chemicals into the local environment are the kinds of impacts that can thwart a project.

Economic decisions made by local and national governments apparently have an impact on people. In the present instance, unemployment seems to lead to an increased mortality from suicide. It is clear, therefore, that economic policy 
decisions made by governments (or by their designated decision makers such as the Federal Reserve Bank in the USA) can have a tremendous impact on the population. We have suggested that those making such decisions should prepare formal "impact" statements in the same way that developers and construction companies are required to do. $^{8} \mathrm{~A}$ focus on solely economic issues may suggest particular actions for public policy makers, while consideration of the psychological and social impact of those actions may change these decisions. Indeed, many European nations have regulations in place preventing companies from laying off employees during hard financial times for the companies, and the Employment Committee of the House of Commons in the United Kingdom has requested memoranda from social scientists concerning the psychological impact of unemployment in order to help them make appropriate decisions.' This should become more common, and it would provide an important role for social scientists in future public policy decisions.

\section{$J$ Epidemiol Community Health} 2003;57:558-559

\section{Authors' affiliations}

D Lester, Psychology Program, The Richard Stockton College of New Jersey, Pomona, New Jersey 08240-0195, USA

$B$ Yang, Department of Economics and International Business, Bennett S Lebow College of Business, Drexel University, Philadelphia, USA

Correspondence to: $\mathrm{Dr} \mathrm{D}$ Lester;

lesterd@stockton.edu

\section{REFERENCES}

1 Platt SD. Unemployment and suicidal behavior. Soc Sci Med 1984:19:93-115.

2 Platt SD. Parasuicide and unemployment. $\mathrm{Br} J$ Psychiatry 1986;149:401-5.

3 Lester D, Yang B. The economy and suicide. Commack, NY: Nova Science, 1997.

4 Lester D, Yang B. Suicide and homicide in the 20th century. Commack, NY: Nova Science, 1998

5 Blakely TA, Collings SCD, Atkinson J. Unemployment and suicide. Evidence for a causal assoication? J Epidemiol Community Health 2003;57:594-600.

6 Lester D, Yang B. Microsocionomics versus macrosocionomics as a model for explaining suicide. Psychol Rep 1991;69:735-8.

7 Ezzy D. Unemployment and mental health. Soc Sci Med 1993:37:41-52.

8 Yang B, Lester D. New directions for economics. Journal of Socio-Economics 1995:24:433-46.

9 Lester D, Yang B. Memorandum. The relationship between unemployment and suicide. Submitted on request to the Employment Committee of the House of Commons, London, UK, 18 Jul 1994.

\section{Research on unemployment and suicide}

\section{A J Kposowa}

\section{Problems and consequences}

M any capitalist economies are characterised by business cycles with concomitant increases in joblessness during recessions and depressions, and reductions in unemployment in periods of economic expansion. In view of the potentially debilitating consequences of joblessness on health and related outcomes, research on unemployment and suicide continues to be relevant in both epidemiology and sociology. One controversy that continues is the issue of selection bias. The essential question that remains unresolved is whether the observed association between unemployment and suicide reported in some studies reflects direct causation or whether there is some variable that is causally prior to both unemployment and suicide.

The report by Blakely et al presents an analysis of the New Zealand Census Mortality Study (NZCMS) that attempts to shed some light on the above question. Using logistic regression models on census mortality linked data on 1.65 million men and women aged 18 to 64 years, they have observed that unemployment is strongly associated with suicide among women and men in the age group 25-64. At the same time, no significant associations were observed in other age groups. In an effort to support a causal argument, the authors have controlled for the usual socioeconomic variables (education and income), and to convince readers that there is no confounding (selection bias) Blakely et al have also reported results of various sensitivity analyses using information from other studies.

The analysis was competently done, but the study is not without serious limitations. Firstly, the key independent variable in the report, employment status is a time varying covariate, but it is not treated as such in the analysis. Failure to account for multiple occurrences even in a given calendar year can distort results by underestimating or overestimating the consequences of joblessness. In short, imprecision and inaccuracies are introduced into the analysis, and despite confidence intervals the validity of conclusions become suspect. Previous studies ${ }^{2}{ }^{3}$ suggest that the effect of unemployment on suicide may be more pronounced immediately after job loss. As time progresses the newly unemployed adjust to their novel status and they may be less inclined to commit suicide. Furthermore, with passage of time previously unemployed people may find work and thus vacate the "unemployed" status. Secondly, it is unknown in the analysis when job loss occurred. All that is known is that at some point before census night, cohort members became unemployed, but the timing of unemployment is unknown. There is also no information on whether they had experienced more than one episode of unemployment.

Blakely et al seem to have linked the mortality information to census data in the three years after census night. ${ }^{1}$ While this practice may have perhaps reduced the problem regarding the transitional nature of employment status, it did not eliminate it because of the long intercensus period. In the time lag between the current census (the one linked to mortality data) and the prior census, people may have still moved across the three categories of employment status.

In view of the above issues, it is imperative that researchers find ways to accommodate peculiarities associated with time varying covariates in cohort and other longitudinal studies. A significant part of the problem in this and most studies of this type is their dependence on official (government collected) datasets. Censuses are not taken primarily for epidemiological research. In many countries enumeration occurs only once in ten or five years (depending on national mandates). As only one enumeration is done there is no provision for follow up data collection on the same people on a weekly or monthly basis. Even if that were possible, the logistics and accompanying financial costs would be prohibitive. One result of this dependence is that very often information is needed by the researcher but it is unavailable in administrative (government) statistics. At 
other times (like in the present situation), data are available but not in the format appropriate for the selected research problem.

Ideally, one would have liked to see controls for mental illness and general health status both of which could directly affect unemployment and suicide. For instance, mentally ill persons may be at higher risk of becoming unemployed; they may also be at higher risk of committing suicide. ${ }^{4}$ Blakely et al admit that they lack such data.

Related to the above, another important flaw in epidemiological and sociological research on unemployment and suicide using census data is in the conceptualisation and measurement of employment status itself. In the New Zealand Census Mortality Study, the employed are those already at work. The unemployed are persons that are actively seeking work and available for work. ${ }^{1}$ Everyone else is placed into a residual category called the "non-active". The primary limitation in this conceptualisation of employment status is that it fails to take into account people who are jobless, but have become discouraged in the labour market and have given up looking for work. Some US sociologists euphemistically refer to this group as "discouraged workers". ${ }^{5}$ Their number is never known, but in periods of severe and sustained economic downturns, it is never negligible especially among racial/ethnic minorities and other marginalised groups.

In view of the above, it is no surprise that Blakely et al ${ }^{1}$ found a highly significant association between non-active status and suicide in two of their multivariate models $(\mathrm{OR}=2.63, \mathrm{CI}=1.63$ to 4.25 for women; $\mathrm{OR}=2.59$. $\mathrm{CI}=1.89$ to 3.55 for men). Although the non-active group includes students, homemakers, the permanently sick, and retired, as it is a residual category of persons not elsewhere classified, it most probably has a large number of persons that had given up looking for work before the census. The odds ratio for the non-active is greater in magnitude than that obtained for the unemployed in both multivariate models. This is noteworthy in view of the fact that the analyses were limited to persons in the age group 25-64 years.

$J$ Epidemiol Community Health 2003;57:559-560

\section{Author's affiliations}

A J Kposowa, University of California at Riverside, USA

Correspondence to: Dr A J Kposowa, Department of Sociology, University of California, 1214 Watkins Hall, 900 University Avenue, Riverside, CA 92521, USA;

ajkposowa@att.net

\section{REFERENCES}

1 Blakely TA, Collings SCD, Atkinson J. Unemployment and suicide. Evidence for a causal association? J Epidemiol Community Health 2003;57:594-600.

2 Kposowa AJ. Unemployment and suicide: a cohort analysis of social factors predicting suicide in the US National Longitudinal Mortality Study. Psychol Med

2001;31:127-38.

3 Preti A, Miotto P. Suicide and unemployment in Italy, 1982-1994. J Epidemiol Community Health 1999;53:694-701.

4 Lönnqvist JK. Psychiatric aspects of suicidal behavior: depression. In Hawton K, Heeringen $\mathrm{KE}$. The international handbook of suicide and attempted suicide. New York: Wiley, 2000: 107-20.

5 Ritchey PN. Explanations of migration. Annual Review of Sociology 1976;2:363-404.

\section{Unemployment and suicide}

\section{E Agerbo}

\section{Is the link always causal?}

S uicide is more frequent among people who are unemployed.' The suicide-unemployment association has been debated since sociologist Emil Durkheim's classic study ${ }^{2}$ over 100 years ago concluded that unemployment increased social isolation, which then raised the risk of suicide. He further concluded that the number of suicides in a society did not have any specific association with the occurrence of mental disorders at the ecological level.

Many studies have suggested that the suicide-unemployment link is causal, or partially caused by a selection process governed by the effect of common unobserved factors, such as mental illness, leading both to unemployment and suicide, or that the link is reverse causal, so that a suicidal behaviour leads to unemployment, or more rarely argued, that there is no indication of unemployment causing suicide. The core problem is that, as Karl Pearson (a founder of modern statistics) said: only correlation and not causation can be estimated from observational data. This viewpoint, however, has recently been relaxed by, for example, Jamie Robins who introduced the concept of counterfactual and by econometricians who for more than 50 years have been using instrumental variables to pseudorandomise individuals to exposure. Professor Judea Pearl's new book is a brilliant introduction to these and other techniques used to strengthen causal reasoning. ${ }^{3}$

Blakely and colleagues say that the suicide-unemployment association found in their paper is likely to be causal. ${ }^{4}$ They argue that the link is not mediated by financial stress (which by the way carried surprisingly little information in the first place), as the incidence related to unemployment is comparatively unchanged in the adjusted regression, and because the odds of linking suicide were almost the same between the most socioeconomically deprived $50 \%$ of small areas compared with the least deprived $50 \%$. This is further used as a vehicle to argue that the association is likely to be underestimated. However, ecological information in a micro data study might introduce "hierarchical" measurement error, which the authors acknowledge by suggesting this as a target for future studies.

As in other studies, ${ }^{56}$ Blakely and colleagues $^{4}$ find that the suicideunemployment association in part is mediated by mental illness, which they primarily conclude from their sensitivity analysis of biases. They further explain that mentally ill people would to a larger degree be non-active on the labour market rather than unemployed, which then suggest a sensitivity analysis for the group of those who are non-active on the labour market. Although Blakely and colleagues ${ }^{4}$ use a set of external information that differs from the information used in the reference by Sander Greenland, the sensitivity analysis is one of the virtues of the paper, as it demonstrates an approach to deal with missing confounder information. Their lowest estimated relative risk of suicide among the unemployed (1.35) is quite similar to the rate found in a study where information on mental illness was included. ${ }^{6}$ This study, on the other hand, includes only information from population based hospital discharge records, and finds also higher suicide rates among the mentally 
ill than the rate used by Blakely and colleagues. ${ }^{4}$

It might be hypothesised that the suicide-unemployment association differs among people who suffer from a mental disorder, as studies have suggested no association ${ }^{7}$ or even a nonsignificant $30 \%$ reduction in risk, ${ }^{8}$ and as individual longitudinal studies of deliberate self harm and unemployment do not present a coherent picture. ${ }^{1}$ One study even finds that the suicide rates increased with increasing income among patients. ${ }^{9}$ This might be the effect of an increased stigma ${ }^{10}$ or because employed patients are in a particularly stressful situation.

As acknowledged by Blakely and colleagues, ${ }^{4}$ their study does not provide strong evidence in favour of the hypothesis, but they try to mend imperfections in their data, and we should encourage studies such as this.

$J$ Epidemiol Community Health 2003;57:560-561

n..................

Author's affiliations

E Agerbo, National Centre for Register-based

Research, University of Aarhus, DK-8000

Aarhus C, Denmark

Correspondence to: Dr E Agerbo; ea@ncrr.dk

\section{REFERENCES}

1 Platt S, Hawton K. Suicidal behaviour and the labour market. In: Hawton K, van Heeringen $\mathrm{K}$, eds. The international handbook of suicide and attempted suicide. New York: Wiley, 2000:309-84.

2 Durkheim E. Sialvmordet: En av sociologiens stora klassisker (Translation of 'Le Suicide').

Uppsala: Argos, 1968

3 Pearl J. Causality: models, reasoning, and inference. New York: Cambridge University Press, 2000
4 Blakely TA, Collings SCD, Atkinson J. Unemployment and suicide. Evidence for a causal association? J Epidemiol Community Health 2003;57:594-600.

5 Agerbo E, Nordentoft M, Mortensen PB. Familial, psychiatric, and socioeconomic risk factors for suicide in young people: nested case-control study. BM 2002;325:74-7.

6 Mortensen PB, Agerbo E, Erikson T, et al. Psychiatric illness and risk factors for suicide in Denmark. Lancet 2000;355:9-12.

7 Appleby L, Dennehy JA, Thomas CS, et al. Aftercare and clinical characteristics of people with mental illness who commit suicide: a case-control study. Lancet 1999;353:1397400.

8 Powell J, Geddes J, Deeks J, et al. Suicide in psychiatric hospital in-patients. Risk factors and their predictive power. $\mathrm{Br} J$ Psychiatry 2000; 176:266-72.

9 Agerbo E, Mortensen PB, Eriksson T, Qin P, et al. Risk of suicide in relation to income level in people admitted to hospital with mental illness: nested case-control study. BM 2001;322:334-5.

10 Byrne P. Psychiatric stigma. Br J Psychiatry 2001;178:281-4. 